\title{
Dietary alkylresorcinols and cancer prevention: a systematic review
}

\author{
Joanna Kruk ${ }^{1} \cdot$ Basil Aboul-Enein $^{2} \cdot$ Joshua Bernstein $^{3} \cdot$ Mariola Marchlewicz $^{4}$
}

Received: 15 November 2016 / Revised: 28 March 2017 / Accepted: 14 April 2017 / Published online: 10 May 2017

(C) The Author(s) 2017. This article is an open access publication

\begin{abstract}
The potential role of alkylresorcinol compound from whole grains for prevention and inhibition of human cancer cell lines has been reported in observational and in vitro studies. The objective of this study was to present an updated review on the association between alkylresorcinols and cancer risk and aspects of their bioactivity with implications for carcinogenesis. Relevant studies were identified by searching PubMed, Scopus, ProQuest, EBSCOhost, SpringerLink, ArticleFirst, Taylor \& Francis, Wiley Online, and ScienceDirect electronic databases using these search terms and key words: alkylresorcinols, cancer, carcinoma, risk. Furthermore, references from retrieved articles were also reviewed. Four observational and 10 in vitro studies were included in the analysis of natural or synthetic alkylresorcinols for anticancer activities. Two prospective studies reported a 52-66\% risk reduction of distal colon cancer at nanomolar alkylresorcinols concentration in plasma; the remaining studies found no reduction of endometrial cancer risk and an approximate $40 \%$ increase in prostate cancer risk. In vitro studies presented inhibition of human colon, breast, lung, central
\end{abstract}

Joanna Kruk

joanna.kruk@univ.szczecin.pl

1 Department of Prevention and Occupational Therapy, Faculty of Physical Culture and Health Promotion, University of Szczecin, Szczecin, Poland

2 Department of Global Health and Development, London School of Hygiene and Tropical Medicine, London, UK

3 College of Graduate Health Studies, A.T. Still University of Health Sciences, Kirksville, MO, USA

4 Department of Aesthetic Dermatology, Pomeranian Medical University, Szczecin, Poland nervous system, adenocarcinoma, hepatocarcinoma, cervix squamous carcinoma, and ovarian cancer cell lines, at micromolar alkylresorcinols concentration. Evidence from prospective studies confirmed significant inverse associations between whole grains intake and distal colon cancer risk. Model studies suggest a high cytotoxicity of alkylresorcinols toward cancer cells. These findings maintain that alkylresorcinols as components of whole grains are likely to find application in cancer prevention; however, the need for intervention studies to confirm their preventive action is warranted.

Keywords Alkylresorcinols · Bioactivity · Cancer .

Prevention - Cytotoxicity

$\begin{array}{ll}\text { Abbreviations } \\ \text { ARs } & \text { Alkylresorcinols } \\ \text { ROS } & \text { Reactive oxygen species } \\ \text { IGF } & \text { Insulin growth factor } \\ \text { LDL } & \text { Low-density lipoprotein } \\ \text { ROO. } & \text { Peroxyl radical } \\ \text { FFQ } & \text { Food frequency questionnaire } \\ \text { IC } & \text { Inhibitory concentration-inhibit cellular prolifera- } \\ & \text { tion by 50\% } \\ \text { PSA } & \text { Prostate specific antigen } \\ \text { OR } & \text { Odds ratio } \\ \text { IRR } & \text { Incidence rate ratio } \\ \text { CI } & \text { Confidence interval } \\ \text { TGI } & \text { Concentration of drugs that totally inhibit cell } \\ & \text { growth } \\ \text { LC } & \text { Concentration of drugs resulting in cell death to } \\ & \text { 50\% } \\ \text { 5-AR } & 5 \text {-Alkylresorcinol } \\ \text { DNA } & \text { Deoxyribonucleic acid } \\ \text { ATP } & \text { Adenosine triphosphate }\end{array}$




\section{Introduction}

There are several environmental factors that influence cancer development. Studies demonstrate an independent effect of dietary patterns on cancer risk which are modifiable by diet. Evidence suggests that diet represents $30-35 \%$ of all risk factors contributing to the onset of cancer. Positive health effects have been reported for vegetables, fruits, and whole grains [1-6]. Whole grain foods, rich in dietary fiber, minerals, vitamins, and phytochemicals, are recognized as agents exerting health protective effects [7]. Much of the research on relationships between diet and cancer risk is based on the hypothesis that high intake of these nutrients rich in antioxidants (e.g., polyphenolic compounds, lignans, vitamins) may affect a number of physiological and pathological processes, like signaling mediated by MAP-kinases, insulin growth factor (IGF-1), nuclear transcription factor (NF- $\kappa \beta)$, cytochrome $\mathrm{P} 450$, and reactive oxygen species (ROS) $[8,9]$. Transformation of healthy cells and tumorigenesis can be linked to increased DNA mutagenesis, decreased apoptosis, increased cell proliferation, inflammation, and several other processes controlled by antioxidants, thus antioxidants can prevent DNA damage and potentially protect against cancer [10-13]. Nonetheless, the scientific evidence on diet-cancer risk interactions is not conclusive $[5,14]$. Over the last two decades, research interest in medicine and functional food production in the application of whole grains and dietary phytoestrogens has increased significantly $[1,15]$. Of particular interest in relation to tumorigenesis is the class of natural compounds, like phenolic lipids also known as alkylresorcinols (ARs) (Fig. 1).

A wide range of biological properties of ARs, including antimicrobial [16], antimutagenic [17], and antioxidant potency have been reported [7, 18]. Epidemiologic evidence demonstrates that consumption of whole grain cereals is associated with positive health benefits such as decreased risk of overweight and obesity, coronary heart disease, diabetes, and some types of cancer [19-24]. There is insufficient evidence to support the association of ARs with decreased risk of cancer because whole grains beside phenolic lipids contain a high number of primary metabolites (e.g., fiber, sulfur amino acids, lignin, oligosaccharides, minerals, vitamins), polyphenols (e.g., phenolic acids, flavonoids, lignans), phytosterols, melatonin, and other bioactive compounds [7, 15, 21, 25]. In addition, each of these compounds exhibits biological actions which are frequently reported in the literature as health protective mechanisms. In view of these facts, the main objective of this review article is to evaluate and present the current
Fig. 1 General structure and common dietary sources of alkylresorcinols ( $R=n$-alkyl or $n$-alkenyl chain)
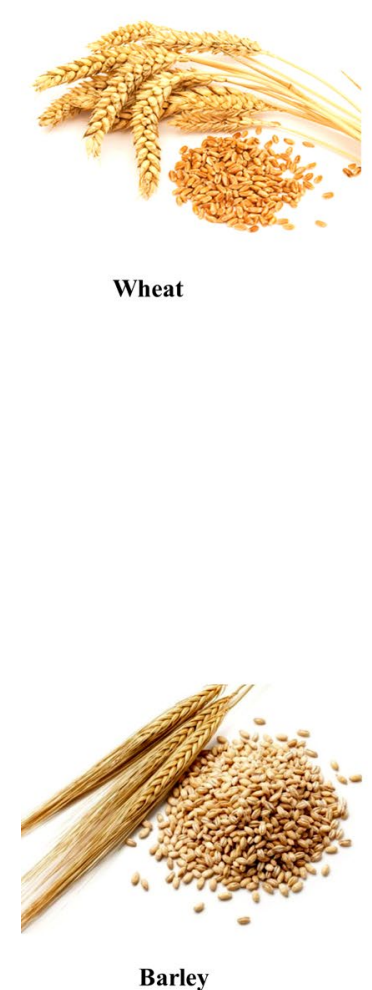

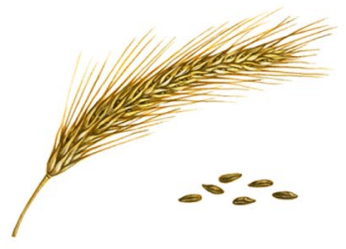

Rye
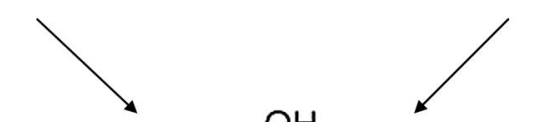

Rye

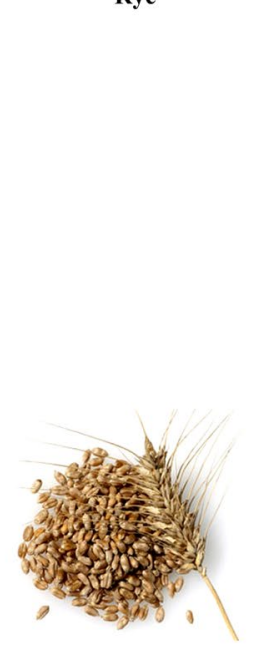

Triticale 
evidence related to ARs and cancer risk and some aspects of the AR's biological activities related to carcinogenesis. Occurrence, pharmacokinetics, extraction, and analysis of ARs will be also presented briefly.

\section{Methods}

An integrative review of the literature was carried out prior to January 2017. Relevant articles were identified by applying search strategies to nine academic electronic databases: PubMed, Scopus, ProQuest, EBSCOhost, SpringerLink, ArticleFirst, Taylor \& Francis, Wiley Online, and ScienceDirect. Search terms and key words included: Alkylresorcinols; cancer; carcinoma; risk. These databases were chosen due to their extensive coverage of biomedical and cross-disciplinary research objectives and scope. All retrieved titles, abstracts, and full-text publications were reviewed and screened for relevance to the topic. Furthermore, references from retrieved articles were reviewed to identify additional applicable publications.

\section{Inclusion/exclusion criteria}

Inclusion criteria for refereed study samples included observational and in vitro studies. Other article types such as conference abstracts, communications, commentaries, editorials, brief reports, position, and hypothesisgenerating statements were excluded. Gray literature and non-refereed publications were also excluded. No language restrictions were imposed. A flowchart of the study screening and selection is presented in Fig. 2.
Fig. 2 Flow diagram of literature search process
538 total citations identified from database search resultsPubMed: 22

Scopus: 24

ScienceDirect: 204

EBSCOhost: 173

SpringerLink: 26

Taylor \& Francis Online: 17

Wiley Online: 37

ArticleFirst: 3

ProQuest: 32

2 citations added after checking reference lists

Eligible citations passed fulltext screening and inclusion criteria $(n=26)$

PubMed: 2

Scopus: 19

ScienceDirect: 4

Wiley Online: 1 


\section{Results}

\section{Prevalence of alkylresorcinols}

This large group of phenolic compounds (1,3-dihydroxy-5- $n$-alkylbenzenes) (about 150 natural occurring ARs) [26] consists of a single phenolic ring with two hydroxyl groups $(\mathrm{OH})$ in the meta-position and odd numbered alkyl side chain $(\mathrm{R})$ which can contain between 13 and 27 carbon atoms with dominance in the range of $\mathrm{C} 15-\mathrm{C} 25$ at position $5 \mathrm{C}$ in the benzene ring [27]. The hydrocarbon chains can contain two double bonds between carbon atoms, ketone, or hydroxyl groups. The chemical structure and length of chains depend on biological origin [28]. The following five major classes of ARs have been reported in whole grain, wheat, and rye: 5-n-alkylresorcinols, 5-alkenylresorcinols, 5-oxoalkylresorcinols, 5-oxoalkenylresorcinols, and 5-hydroxyalkenylresorcinols [15]. Alkenylresorcinols, the phenolic lipids with unsaturated hydrocarbon side chains, accounted for about $20 \%$ of the total amount of ARs as were identified and quantified by Söderholm et al. in rye bread [29].

These compounds are present in several plant families and some bacteria, fungi, algae, and marine sponges [27]. Among food plants, ARs occur in the whole grain or bran fractions; they are distributed in the outer cuticula of the testa and inner cuticula of the pericarp in rye, wheat grains, and in smaller amounts in barley. Various cereal grains are grown in different countries, depending on climatic conditions. In the regions with cold temperature and poor quality soils, rye is an important cereal grain, although cultivation of rye constitutes just $3 \%$ of the worlds wheat production. The AR content, its chemical structure, and the homologue ratios differ between cereal grains and are dependent on several environmental factors like geographical region, soil composition, fertilization, and cultivation [30-32]. ARs occur mainly in the outer parts of whole wheat and rye products at high concentrations (200-4000 $\mu \mathrm{g}$ per gram of dry matter) and at low concentration in refined flour or products $(40-280 \mu \mathrm{g}$ per gram of dry matter) [33-35]. ARs are proposed as valid biomarkers of whole grain and rye consumption of cereal grains which are the main human food crop [30, 36-39]. The ARs concentration is dependent on grain type. For example, rye contains about $797-1231 \mu \mathrm{g} / \mathrm{g}$ of dry matter, wheat $220-650 \mu \mathrm{g} / \mathrm{g}$ of dry matter, and barley $40-110 \mu \mathrm{g} / \mathrm{g}$ of dry matter [40]. A relative high concentration (489-1429 $\mu \mathrm{g} / \mathrm{g}$ of dry matter) of ARs occurs in wheat bran [15] of which human consumption has increased over the years [41]. Among cereal grains such as rye, wheat, and durum wheat, rye is richest in ARs [42].

\section{Alkylresorcinols during grain processing}

In contrast to whole grain foods, refined products contain only trace-concentrations of AR [15]. Grain processing (e.g., milling, cooking, fermentation) changes the nutritional content of cereal grains by fragmentation of the grain matrix and gelatinization of starch granules [7, 43]. Due to occurrence of ARs, vitamins, minerals and trace elements, and antioxidants in the outer parts of the grain, the final nutrient content will be dependent on the extent to which the outer parts are removed during processing. For example, refining whole grain wheat may result in the loss of about $58 \%$ of fiber, $79 \%$ of zinc, $79 \%$ of vitamin E, $83 \%$ of magnesium, and $92 \%$ of selenium [7]. High-temperature processing of cereal grains decreases AR content in grain food due to denaturation and degradation [15].

\section{Anti-nutrients in grain cereals}

Notably, whole grain cereals also contain anti-nutrients which exert both adverse and positive health effects [7, 44-46]. Anti-nutritional factors can reduce nutrient intake, design, absorption, and utilization. The factors are naturally present in grains or they originate from contamination (fungal origin, related to soil and other environmental influences). The most important are phytic acid, lectins, tannins, saponins, inhibitors of proteases, and amylases which modify the nutritional values of cereals. For example, tannins and the phosphorus compound phytic acid can bind iron, calcium, and zinc; lectins can damage the intestinal microvilli and interact with antibodies, thus stimulating an immune system response. There is significant interest in understanding how processing influences concentrations of bioactive phytochemicals present in whole rye, wheat, and barley from different cultivations and in obtaining functional ingredients rich in ARs [34, 47]. Therefore, several reduction strategies have been developed to reduce antinutrients and improve whole grain foods. For example, processing of cereal grains through cooking, roasting, fermentation, and germination may decrease concentration of tannins and phytic acid [3, 7].

\section{Pharmacokinetics of alkylresorcinols}

According to a scheme proposed by Landberg et al. [48], presenting the pathways of AR absorption, distribution, metabolism, and excretion, the compounds are absorbed in the small intestine, although there is no clear evidence describing the mechanism of absorption. The authors suggested that in the intestinal cells ARs can be assembled into chylomicrons, followed by their transportation into the lymphatic system. The compounds may also be absorbed 
directly during transfer to HDL (high-density lipoprotein), LDL (low-density lipoprotein), and VLDL (very low-density lipoprotein) fractions. Next, from lipoproteins ARs are distributed into erythrocyte membranes, wherein the plasma-erythrocyte ratio is dependent on the chain length ranging from 0.5 to 1.3 , being higher for longer homologues. An analysis of AR level in erythrocytes and in plasma showed that their concentration was maximal after about $13 \mathrm{~h}$ post-feeding (300-500 nM) and at $7 \mathrm{~h}$ $(3365 \mathrm{nM})$, respectively when ARs are consumed several times daily. The ARs absorption level and elimination halftime, the time at which the excretion rate decreases to half of the maximal excretion rate in humans and animals, are the individual features changing at different value ranges between individuals [26]. Similar to tocopherols, ARs are eliminated from circulation with an apparent half-life about

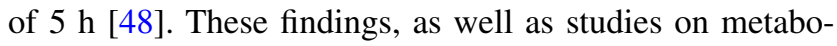
lism of resorcinols and 4-n-nonylphenyl, propose similar metabolism of ARs as tocopherols including two phases. In phase I, ARs are metabolized by the introduction of a hydroxyl group (HO) at the end of the alkyl tail through omega-oxidation catalyzed by cytochrome $\mathrm{P} 450$ isoenzyme CYP4F2. Next, the HO group is oxidized to a carboxylic acid, followed by successive $\beta$-oxidation, thus making the alkyl chain shorted, and two main water-soluble metabolites: 3-(3,5-dihydroxyphenyl)-1-propanoic acid (DHPPA) and 3,5-dihydroxybenzoic acid (DHBA) are final products of this phase [42-48]. In phase II, ARs and their intermediate and final metabolites are partially conjugated by a polar group to xenobiotics or endogenous compounds. Conjugation with glucuronide sulfate groups and amino acids is the key reaction improving urinary excretion of AR metabolites. Two AR metabolites DHPPA and DHBA were detected in plasma and human urine $[29,49,50]$ and considered as biomarkers of whole grain wheat and rye intake. For example, Söderholm et al. observed maximum exertion rates of 5-6 h for DHPPA and DHBA metabolites, and significant amounts were still measurable at $25 \mathrm{~h}$ in human urine [29]. Recently, new ARs metabolites 3,5-dihydroxycinnamic acid (DHCA), 5-(3,5-dihydroxyphenyl) pentanoic acid (DHPPTA), 3,5-dihydroxycinnamic acid amide (DHCA-amide), and 2-(3,5-dihydroxybenzamido)acetatic acid (DHBA-glycine) were developed in human urine samples [51, 52]. Although their concentrations in urine were considerably lower than those of DHPA and DHPPA metabolites [52], they are suggested as potential biomarkers for whole grain wheat and rye intake [51, 52].

\section{Extraction and analysis of alkylresorcinols}

For analytical studies, ARs require previous extraction and identification. The extraction process from cereal grains is important for accurate quantification of AR content in whole grain food products as they are potentially phytochemicals for use in disease prevention. Several methods including modern technologies have been applied to the extraction of ARs from plant material, mainly conventional solvent extraction, ultrasonic-assisted extraction (UAE), and subcritical fluid extraction (SFE) [15]. Briefly, the conventional extraction methods include Soxhlet extraction, stirring, distillation, manual mixing, and percolation. The extraction methods use refluxing samples with different organic solvents like acetone, ethylacetate, hexane, and propanolwater mixture $(3: 1)$ because ARs are insoluble or poorly soluble in water. Extraction methods are expensive and time consuming (1-48 h). SFE is a technique that uses a supercritical fluid as the extracting solvent and carbon dioxide $\left(\mathrm{CO}_{2}\right)$ is the most used supercritical fluid $[53,54]$. The fluid is allowed to flow at a desired pressure of $40 \mathrm{MPa}$ through a milled sample at an extracting temperature of $40-80{ }^{\circ} \mathrm{C}$. The $\mathrm{CO}_{2}$ fluid is often modified using ethanol or methanol to increase the extraction yield. The major advantage of SFE- $\mathrm{CO}_{2}$ is high selectivity which shortens extraction time and lowers organic solvent costs compared to conventional extraction methods. Similarly, UAE is an efficient and inexpensive modern extraction technique of increased selectivity and kinetics. In UAE extraction, ultrasound is used to break the cell membranes. Diffusion of solvent through membranes is accelerated, thus the release of cell contents is facilitated [55]. It is worth noting that an important property of compounds containing phenol group, like antioxidant potential, may be influenced by the extraction solvent and extraction time [56]. However, no qualitative or quantitative differences in AR extradition were found after applying supercritical $\mathrm{CO}_{2}$ and conventional extradition using ethyl acetate [57]. To determine the AR structure-activity relationship, synthetic compounds are prepared using Grignard and Wittig reactions [58]. Colorimetric methods, thin-layer chromatography, high-performance liquid chromatography, gas chromatography, mass spectrometry, and nuclear magnetic resonance are the techniques used for ARs separation, identification, structure establishment, and qualitative and quantitative analysis [15, 54, 59].

\section{Biological activity of alkylresorcinols}

ARs exhibit a wide range of biological properties due to their amphiphilic properties resulting from the presence of polar water-soluble $\mathrm{OH}$ groups attached to the benzene ring and the presence of a water-insoluble hydrocarbon chain. Current evidence for the biological importance of ARs is based mainly on in vitro examination. Three kinds of positive effects of whole grain cereals are identified: nutritional, mechanistic (due mainly to the fiber content), and antioxidant (due to ARs and phenolic acids) [39, 60]. 
Detections of ARs or their main metabolite concentration in blood plasma, erythrocytes, adipose tissue, and in urine are used to estimate whole cereal intake. Several studies reported positive correlations between whole grain intake and the presence of ARs in plasma or their urinary metabolites [36, 51, 61-69]. Finding of in vitro studies have shown that ARs exhibit a broad range of bioactivities including a high affinity to liposome and erythrocyte membranes increasing their permeability, antifungal, antimicrobial, and anticancer abilities [70-78]. ARs can potentially affect all processes regulated by enzymes; this suggests that ARs may exhibit anti-oxidative, anticancer, and antimutagenic activities, induction of apoptosis, and inhibition of some enzymes activities including lipoxygenases, monoamine oxidase, tyrosinase, $\mathrm{Ca}^{2+}$-ATPase, $\alpha$-glucosidase, dehydrogenase, DNA polymerase $\beta$, and lipase in the adipose tissue cells. ARs may also reduce adipose triglyceride, decrease copper-induced oxidation of LDL, inhibit DNA-strand scission, and limit nucleic and protein synthesis in thymocytes $[42,71,72]$. In vitro experiments show an inhibition of the human $20 \mathrm{~S}$ chymotrypsin producing proteasome activities by several synthetic ARs and their homologues with a high potency. This human proteasome includes the catalytic core of a proteinase complex playing several important functions in cells such as controlling proteins p53, p27, and cyclin B levels and the ATP-dependent ubiquitin-mediated protein degradation [58].

Whole grains can improve insulin sensitivity due to their low glycaemic index [49]. Biskup et al. reported that only whole grain intake dominated by rye consumption may be important for type 2 diabetes mellitus prevention based on case-control study (931 cases, 931 controls) [65]. Ross et al. reported ARs can regulate with the high potency the $\gamma$-tocopherol and cholesterol concentrations in rat livers [79]. Further, the researchers found high doses of AR intake decreased excess hepatic lipids which can lead to hepatic insulin resistance and type 2 diabetes and increased concentrations of $\gamma$-tocopherol caused by slower metabolism [80]. In turn, a large population-based intervention study reported whole grain consumption is linked with decreased concentration of non-esterified fatty acids in plasma [36]. Also, Söderholm et al. found decreased peroxidation of LDL in the presence of copper ions in humans after 4 weeks of rye bread consumption [81]. Considering the antioxidant potential of ARs, it is worth noting that this activity is estimated at $10 \%$ of $\alpha$-tocopherol antioxidant capacity, and the hydrogen donation ability of ARs corresponds to $30 \%$ of that exhibited by ferulic acid [36, 42 , 82-85].

Some reports indicate weak direct antioxidant activities of ARs due to their hydrogen atom donor and free radical scavenging activities [60, 82, 83], but note a strong protective action in phospolipid bilayers, such as inhibition of linolenic acids oxidation and protection against $\mathrm{H}_{2} \mathrm{O}_{2}$-induced oxidation of erythrocytes [42]. The weak direct antioxidant power of ARs using the ferric reducing ability of plasma and DPPH assays was observed by Parrika et al. [82] who reported antioxidant activities of several ARs with chains lengths C15:0, C17:0, C19:0, C21:0, and C23:0 using the HT29 human colon cancer cells. ARs were found to increase the self-protection properties of these cells against DNA damage caused by $\mathrm{H}_{2} \mathrm{O}_{2}$ or genotoxic fecal water samples. Parrika et al. also observed a strong protective effect of these compounds against the $\mathrm{Cu}$ ion-induced oxidation of low-density lipids. Notably, lipid peroxidation is currently considered as the main biochemical mechanism involved in cell damage [13, 86]. Peroxidation of lipids is a chain reaction with repetitive $\mathrm{H}$ abstraction by hydroxyl radical and peroxyl radical. The main target is methylene group of polyunsaturated lipids. An addition of molecular oxygen $\left(\mathrm{O}_{2}\right)$ to the alkyl radicals resulting in generation of peroxyl radicals (ROO) leads to their oxidative destruction [86]. The antioxidant property of ARs as polyphenolic compounds originates from the ability of their hydroxyl groups to donate $\mathrm{H}$ to a free radical, or to donate one electron to an alkyl free radical, which breaks the chain reaction of lipid peroxidation. Thus, ARs may modulate cellular redox state and protect proteins, phospholipids, DNA, RNA, and carbohydrates against peroxidation [82, 84, 85, 87].

There are no oral dosing studies that examine pure ARs in humans [38]. Only a few dietary clinical intervention trials have studied the effect of whole grains intake on health [20, 88-91]. For example, in a 12-week observational dietary intervention trial $(n=79)$, Kristensen et al. examined the effect of replacing refined wheat with whole grain wheat on body weight and percent body fat [90]. The outcome suggested intake of whole grain products may cause a greater reduction in fat mass percentage but was not associated with body weight change. Moreover, total and LDL cholesterol in serum was found to be increased in refined wheat consumers compared to whole grain wheat consumers (5.91 vs. $5.59 \mathrm{nM}, p=0.02$ and 3.96 vs. $3.73 \mathrm{nM}$, $p=0.02$, respectively). In turn, Tighe et al. found that daily intake of three portions of whole grain foods reduced cardiovascular disease in middle-aged people [89].

\section{Prospective studies}

Four observational studies [69, 92-94] were included in analysis of the association of ARs intake with cancer risk, among which two studies [92, 93] involved colorectal cancer. One study dealt with prostate cancer [69] and one study [94] with endometrial cancer (Table 1). The first study on colorectal cancer included a large, multicenter cohort with more than one million individuals from 10 European 


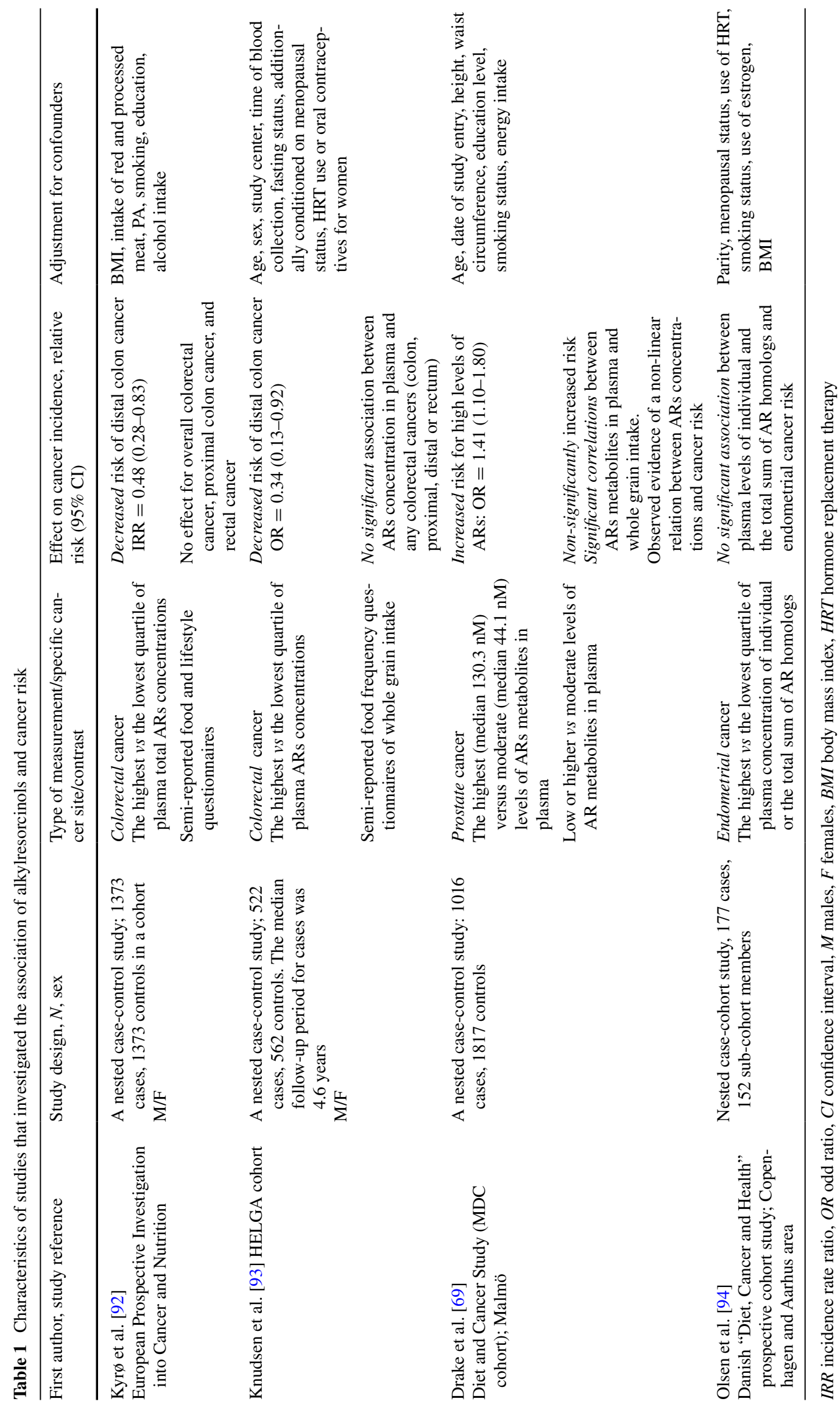


countries [92]. Total plasma concentration defined as a sum of plasma AR homologues C17:0, C19:0, C21:0, C23:0, and $\mathrm{C} 25: 0$ was analyzed in matched case-control pairs. The incidence rate ratio (IRR) of distal colon cancer was reduced by $52 \%$ among individuals with AR concentrations in plasma $>99 \mathrm{nM}$ in men and $>84 \mathrm{nM}$ in women (78 cases, 114 controls). Also, a 17\% reduction in IRR of colon cancer was reported for Scandinavian participants (252 casecontrol pairs). The investigators noticed an inverse relationship between total plasma AR concentrations and colon and distal colon cancer which occurred only in individuals from areas where intake of ARs is high, stable, and frequent, i.e., in the Central Europe and Scandinavia.

The second study on the AR-colorectal cancer relationship examined levels of plasma AR homologues (C17:0, C19:0, C21:0, C23:0, and C25:0) and also used the food frequency questionnaire (FFQ) of whole grain intake [93]. The study included three cohorts: The Norwegian Women and Cancer Study, the Northern Sweden Health and Disease Study, and the Danish Diet, Cancer, and Health Study (a research project on Nordic health effects of whole grain consumption, HELGA). Approximately one hundred twenty thousand men and women aged 30-64 years experienced a 64\% decreased risk of distal colon cancer (198 case-control pairs) reported after comparing the highest quartiles ( $>118.6 \mathrm{nM}$ for men and $>91.7 \mathrm{nM}$ for women) with the lowest $(\leq 35.3 \mathrm{nM}$ for men and $<27.5 \mathrm{nM}$ for women) of AR plasma concentrations. Investigators suggested that usage of both assays, i.e., plasma ARs detection and FFQs of whole grains intake, slightly increases the precision of the study compared to a measure of the association whole grain products intake-cancer risk, using only an FFQ as the exposure measurement. This suggestion was based on finding no significant relationship between wholegrain intake and colorectal cancers when an FFQ was used as an assay.

Only one observational study [69] was identified and included in the comparative analysis between the highest and lowest levels of plasma AR metabolite concentrations and the risk of prostate cancer that estimated the doseresponse (Table 1). The study analyzed prostate cases from the Swedish MDC cohort; the odds ratio among men was 1.41 (1.10-1.80) of which plasma AR metabolites concentrations ranged from 93.0 to $596.2 \mathrm{nM}$ (226 cases) compared to those which plasma AR metabolites concentration ranging from 34.1 to $55.8 \mathrm{nM}$ (179 cases). A slightly higher significant risk was found for low-risk prostate cancer (46\%); although the positive association between AR metabolite concentrations and prostate cancer risk had no linear shape. Interestingly, the positive associations of fiber and whole grain intake with prostate cancer was found by Nimptsch et al. in the Health Professionals Follow-up Study (hazard ratios, $\mathrm{HR}=1.13 ; 95 \% \mathrm{CI}=1.03-1.24,49,934$ cases) which lacks statistical importance after restriction to PSA screening [95]. Investigators also observed nonsignificant increased ORs among 647 cases with low risk of prostate cancer and 353 cases with high risk, and for 465 cases with symptomatic prostate cancer. Further, significant moderate correlations between AR metabolites and whole grain products intake were found. The results from this study led investigators to conclude high whole grain intake does not reduce risk of prostate cancer.

A case-control study of the Danish postmenopausal women aged between 53-60 years including 177 endometrial cancer cases and 152 sub-cohort members as a control group evaluated concentrations of AR homologues (C17:0C25:0) in their plasma [94]. Median AR concentration of $78 \mathrm{nM}$ and a lack of statistically important differences between cases and controls with regard to the AR concentration in plasma were found. Investigators confirmed that rye bread consumption was the primary determinant of AR levels and elevation of plasma AR concentrations in nonfasting blood samples. A group of 360 postmenopausal Danish women had the same level of ARs for the joined controls and endometrial cancer cases $(n=176)$ [62].

\section{Cytotoxic activities of alkylresorcinols}

Ten in vitro studies $[58,84,96-103]$ were identified and included in the analysis of natural and synthetic ARs for activities that inhibit growth of human cancer cells (Table 2). The studies focused on isolation and identification of naturally occurring ARs and their synthesis. Two studies $[58,96]$ reported isolation of ARs from wheat bran, a synthesis of several dozens of ARs and their evaluation for growth inhibitory potential against human colon cancer cell lines HCT-116 and HT-29, when treated with various concentration of ARs extracted from wheat bran oil [96]. Investigators examined a series of ARs having different site chain lengths (synthetic including those of short to moderate length side chain: C9:0, C11:0, C13:0, C15:0, C17:0 [58] and those isolated from wheat bran oil: $\mathrm{C} 17: 0-\mathrm{C} 25: 0$ ) [96] (see Table 2). The inhibitory effect on the colon cell lines growth was reported as an $\mathrm{IC}_{50}$ (the half maximal inhibitory concentration as a measure of the activity of AR in inhibiting cancer cell growth). The observed cytotoxic effect was dependent on chemical structure of ARs, being weaker for the compounds with the longer alkyl site chain $(C>17)$ and dependent on type of colon cancer cells HCT-116 or HT-29, with $\mathrm{IC}_{50}$ values about $15 \mu \mathrm{M}$ (C13:0 and $\mathrm{C} 15: 0)$ and approximately $25 \mu \mathrm{M}$ for compounds C:13 and C15:0, respectively [58]. ARs C13:0 and C15:0 were the most effective as colon cancer cell growth inhibitors, and hydroxyl groups in meta-position at $\mathrm{C} 1$ and $\mathrm{C} 3$ on the aromatic ring played an important role in inhibition of cancer cell growth. Investigators also found wheat bran 


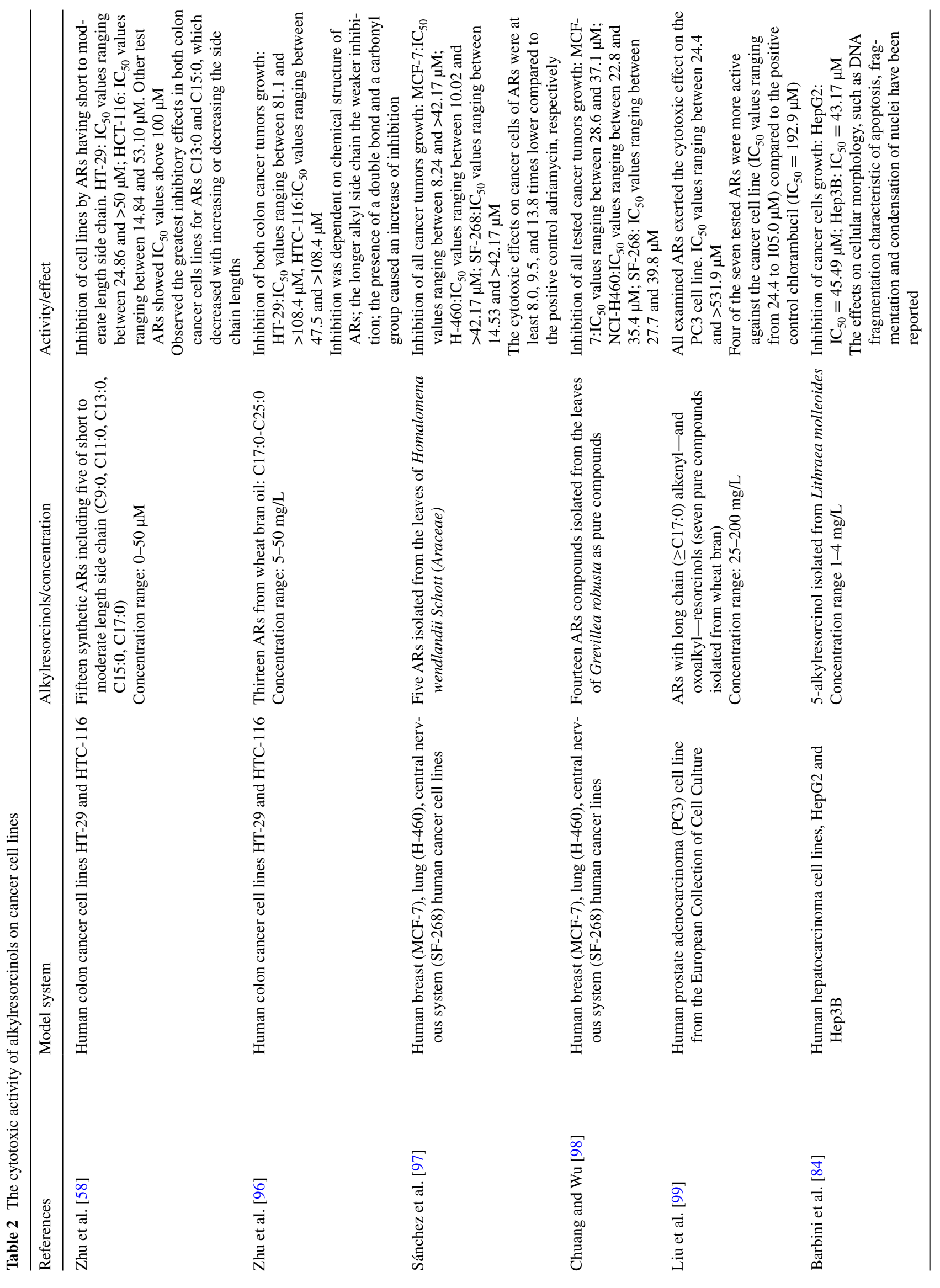




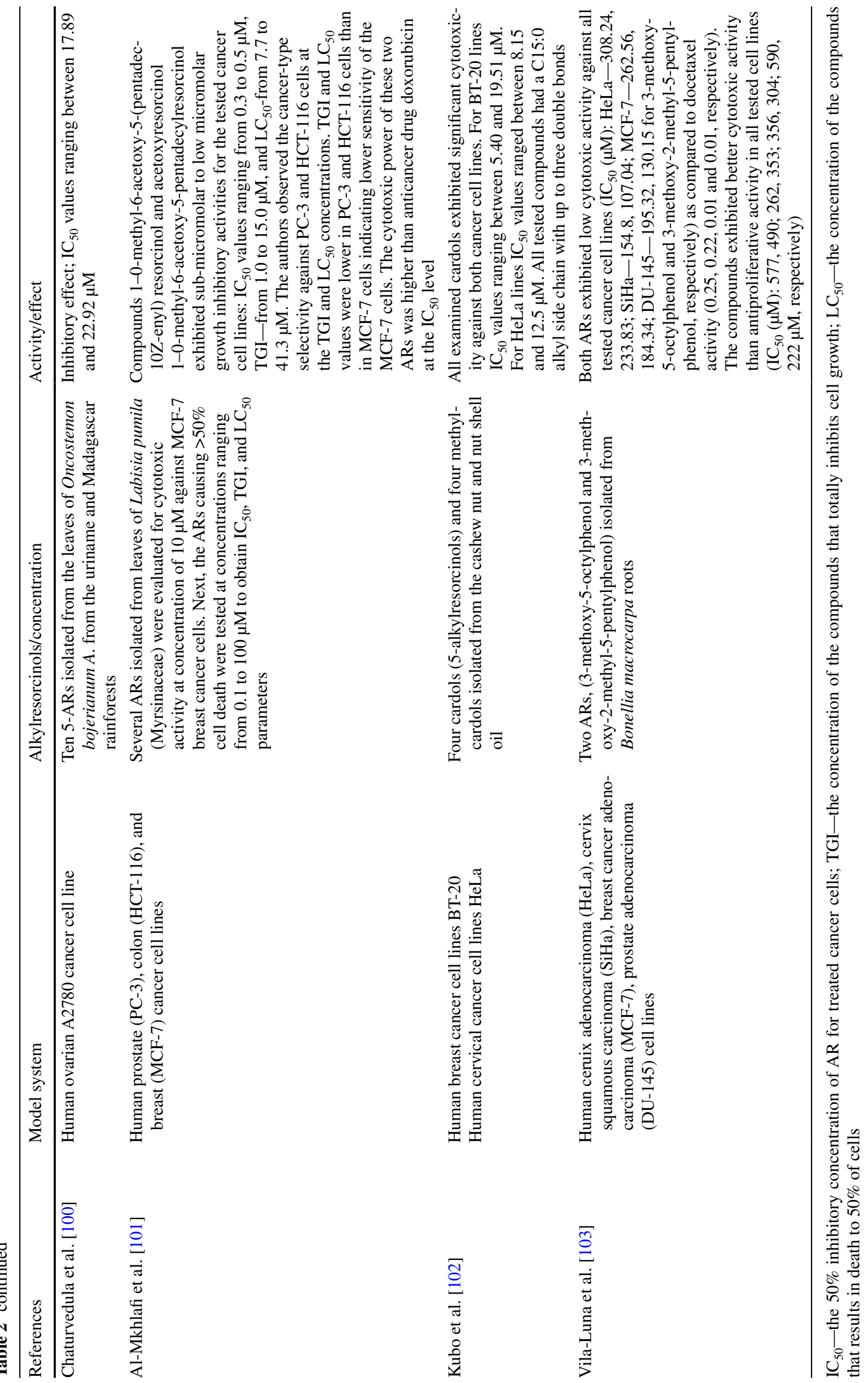


oil fractions containing 5- $n$-alk(en)ylresorcinols exerted the strongest inhibitory effect on the proliferation of human colon cancer cells [96], however their ability to inhibit colon cancer cell lines was lower than synthetic ARs.

In other research, ARs were responsible for the inhibition of human breast, lung, and central nervous system cancer cell growth [97]. The compounds cytotoxicity toward cancer have been presented on MCF-7, H-460, and SF-268 cell lines using five isolated natural ARs. Importantly, the isolated ARs exhibited at least an $800 \%$ stronger inhibitory effect on the tested cancer cell lines than the commonly known cytostatic adriamycin. This study confirmed the findings of Zhu et al. [96] that free phenolic hydroxyl groups of ARs play important role in anticancer action. These findings confirmed also previously published evidence on an inhibitory effect of 14 ARs isolated from leaves of a tropical ornamental tree on human breast carcinoma, lung carcinoma, and central nervous system carcinoma cells [98]. This study observed slightly lower $\mathrm{IC}_{50}$ values in the human lung tumor cell line (NCI-H460) compared to the human breast tumor and human central nervous system cancer cell lines. Investigators suggested the comparable values of $\mathrm{IC}_{50}$, obtained during the cytotoxic evaluation of ARs, can attest that the alkyl chain structure (straight or cyclic) has no effect on cancer cell inhibition. In turn, a study by Liu et al. confirmed in vitro anticancer effects of ARs using human prostate adenocarcinoma (PC3) cells [99]. Liu et al. isolated seven pure ARs from wheat bran and four exhibited strong inhibitory capacity against the growth of PC3 cells; the latter compounds C17:0, C19:1, C21:1, and C23:0xo were the minor ARs with low yield in the isolation process. In conclusion, Liu et al. suggested their results are the first in the literature showing the cytotoxicity of ARs with a longer chain than C17:0 isolated from wheat bran.

Another study demonstrated the cytotoxic effect of 5-alkylresorcinol (5-AR) isolated from L. molleoides leaves in the human hepatocarcinoma cell lines HepG2 and Hep3B [84]. Treatment of both cell lines with 5-AR for $24 \mathrm{~h}$ resulted in induction apoptosis, DNA fragmentation, and nuclear condensation. Cell death observed in both cell lines tested included AR concentration-dependent where $\mathrm{IC}_{50}$ values found for HepG2 and Hep3B were similar. Investigators indicated an important property of 5-AR as of an inductor of apoptosis independently on a p53 pathway (p53 gene is the most commonly mutated gene in hepatocellular cancer). The ability of ARs to inhibit the growth of ovarian cancer cells has been reported by Chaturvedula et al. [100]. Effects of eight new 5-ARs isolated from leaves of Myrsinaceae and two known early ARs on the A2780 mammalian ovarian cancer cell line were examined. All compounds inhibited the growth of the cell line; the inhibitory effect was concentration-dependent, and $\mathrm{IC}_{50}$ values were comparable (17.89-22.92 $\mu \mathrm{M})$. This finding suggests the tested compounds exhibited similar activity toward the cancer cells and, according to the researchers, the activity depends mainly on the basic skeleton of the 5-ARs.

The ability of ARs to inhibit the growth of prostate, colon, and breast cancer cells has been confirmed by AlMeklafi et al. [101]. Twelve isolated ARs from an important medicinal herb in Malaysia were tested and two ARs (structurally very closely related) exhibited the most cytotoxic activity against PC-3, HCT-116, and MCF-7 human cancer cell lines, and were more active than doxorubicin at the $\mathrm{IC}_{50}$ level. The compounds showed cancer cell-type selectivity against PC-3 and HCT-116 cells at concentration which totally inhibits cell growth and concentration which results in cell death of up to 50\%. Both compounds had a substituted aromatic ring by hydroxyl, methoxyl, and acetyl groups and C15:0 alkyl or alkenyl side chain with one double bond. According to Al-Meklafi et al., the presence of the double bond had no effect on the compound cytotoxic activity [101].

The studies of Sánchez et al. [97], Chuang and Wu [98], and Al-Mekhlafi et al. [101] confirmed the findings of Kubo et al. [102] on cytotoxicity of ARs against human breast cancer cell lines. Kubo et al. found that ARs and their methyl derivatives also exhibited significant cytotoxicity against human cervical cancer cell lines HeLa. Also, a study by Vila-Luna et al. [103] observed the cytotoxic effect of two phenolic lipids isolated from roots of $B$. macrocarpa against several human cancer cell lines including cervix (HeLa, SiHa), breast (MCF-7), and prostate (DU-145).

\section{Discussion}

This review article focuses on a relatively new research area because AR benefits have attracted significant interest in the last two decades. Evidence from different model studies show ARs are phenolic lipids abundant in several plant families, some bacteria, fungi, algae, and marine sponge, mainly as homologues with alkyl chains (C15:0-C25:0), though many studies examined derivatives having unsaturated and oxygenated side chains. Dietary ARs are easily absorbed by humans and several studies focused on their detection in blood plasma, adipose tissue, erythrocytes, and their metabolites in urine. Evidence has demonstrated that AR content or their metabolites in humans is proportional to intake of food products containing whole grains. Thus, there is rich evidence on usefulness of plasma and urine AR metabolite measurements as biomarkers of whole grain food, mainly whole grain wheat and rye consumption [37, $38,42,46,47,49,62,65,67]$. Studies which analyzed AR occurrence, absorption, metabolism, and excretion reported 
their presence at micromolar concentration in plasma being the highest after cereal grain intake and at nanomolar concentrations at fasting conditions. All studies confirmed that a refining process leaves only trace amounts of ARs in food products. Phenolic compounds like ARs can potentially affect a number of physiological and pathological processes related to metabolism and immune system functions [71, 72, 104-111].

Results of model studies indicated that ARs which can affect all cellular processes regulated by enzymes, affect genotoxicity, suppress an adipocyte lipolisis, have a high affinity to erythrocyte membranes, exert indirect antioxidant activity, and have cytotoxic effects on cancer cell lines [58, 80, 82, 96-99, 103, 105, 112, 113]. Evidence for AR bioactivity in vivo is limited to a few dietary clinical intervention trials which examined the effect of whole grains intake [88-90, 114]. The majority of studies highlight cereal grains as an important source of many other bioactive compounds, such as benzoxazinoids, lingnans, phenolic acids, tocols, and phytosterols that are known to reduce cancer in humans, as recently reviewed $[1,15,19$, 37, 73, 74, 114-116].

Results based on two case-control studies of lower distal colon cancer risk with high plasma AR concentrations (Table 1) are consistent with a meta-analysis of six prospective and nested case-control studies which reported the reduced summary relative risk of colorectal cancer after three servings daily of whole grains $(\mathrm{RR}=0.83)$ [5]. Also noteworthy, the latest systematic review of 12 studies on cancer mortality with 34,797 deaths related to whole grain intake (3 studies) or whole grains product intake (9 studies) found a dose-dependent reduced risk of cancer mortality $(\mathrm{RR}=0.82)$ [107]. Analysis showed that men with high concentrations of AR metabolites in plasma had increased prostate cancer risk. In turn, a lack of risk reduction was observed in case of endometrial cancer. These findings are consistent with evidence from in vitro studies with regard to colon cancer but not prostate cancer (Table 2). In vitro evidence showed inhibition of colon, breast, lung, and central nervous system human cancer cell growth, and the ARs cytotoxicity against the prostate adenocarcinoma, hepatocarcinoma, cervix adenocarcinoma, cervix squamous carcinoma, and ovarian cancer cell lines. We noticed that the chain length of ARs was important for the ARs ability to inhibit cancer growth, with shorter chains like C13:0, C15:0, and C17:0 appearing to have the highest potency of cancer inhibition which is in line with previous findings [105]. Long chain ARs may be absorbed to a lesser extent compared to the shorter-chain homologs. The listed $\mathrm{IC}_{50}$ values in Table 2 allow us to suggest high levels of ARs appeared to be toxic to cancer cells. These findings are consistent with evidence from the model studies which reported a lack toxicity of ARs of moderate concentration, i.e., of 5-20 $\mu \mathrm{M}$ toward to healthy HepG2 or 3T3-L1 cells $[42,107,113]$.

The observed differences between findings reported in Tables 1 and 2 may be explained by a relative short half-life time ( 4-5 h) limiting the precision of plasma AR concentration detection, especially in populations in which food rich in rye and whole grain components is not consumed daily [93], although Landberg et al. reported a high correlation coefficient between plasma AR concentration and whole grain wheat and rye intake during a 6-week intervention study [35]. There are several hypothesized mechanisms by which ARs can exert inhibition of cancer risk, although the mechanisms do not consider the possible interaction and synergy between the functional components of a diet, like phenolic compounds, fiber, lignans, phytosterols, and vitamins, which are reported to exhibit beneficial effects on human health including cancer prevention [15, 23, 37, 46]. These potential interactions need to be verified with further research.

In vitro studies revealed the dose-response cytotoxicity of ARs toward many cancer cell lines is due to their strong effect on cellular morphology, such as DNA fragmentation and nuclear condensation, among others; this action can lead to apoptosis [84]. Increase in p53 concentration plays a key role in the expression of pro-apoptotic proteins [104]. The apoptotic pathway has been confirmed by Barbini et al. who observed an induction of apoptosis by $5 \mathrm{AR}$ in HepG2 and Hep3B cells [84]. The group further underlined an important feature of 5-AR for hepatocellular carcinoma therapy, i.e., its ability to trigger apoptosis independently on p53 or Fas phenotypic profile as they observed in Hep3B cells. Also, other research groups have maintained the anticancer effects of ARs are explained by enhancing apoptosis in genotoxically damaged lymphocytes [72]. Some studies provide insight to the ARs structure-dependent relationship finding an important role of free hydroxyl, methoxyl, acetyl, or methyl groups on benzene rings for observed cytotoxicity [98, 102, 103]. For example, the comparable $\mathrm{IC}_{50}$ values observed in cytotoxicity of 14 pure 5-ARs by Chuang and $\mathrm{Wu}$ [98] were partially explained by their antioxidant properties due to scavenging reactive oxygen species and/or inhibition of enzymes involved in the formation of free radicals under physiological conditions [70]. Alkylresorcinols contain two hydroxyl groups placed in meta-position of the phenolic ring, thus they have a week direct antioxidant potency. However, under alkaline conditions and in the presence of transition metal ions, e.g., $\mathrm{Cu}$ and $\mathrm{Fe}$, ARs may be converted to trihydroxyalkylbenzenes-the compounds of a high antioxidant activity able to produce superoxide anion radicals and further hydrogen peroxide and hydroxyl radicals which can damage DNA, proteins, and lipids [72, 106, 108]. Moreover, the next important reported property of ARs that may also be 
clinically significant is a slower metabolism of these compounds under pathological conditions [67].

Results from this study agree with findings of RCTs which demonstrated that participants receiving whole grain interventions had reduced fasting concentrations of insulin and glucose and reduced levels of total and LDL cholesterols, among other potential benefits which can be important for reduction of inflammation and certain cancers protection, as reviewed by Ye et al. [78]. The evidence for the potential role of whole grain food intake for general health benefits and mortality prevention [107] recommends increased consumption of whole grain cereal food products in most countries [117-119]. According to an expert panel report on dietary recommendations [120], at least $8 \mathrm{~g}$ of whole grains per about $30 \mathrm{~g}$, without a fiber, (or at least $51 \%$ of total weight as whole grain content) is required as a minimum content of whole grains food. The recommended quantities of daily whole grain cereal product consumption vary considerably between countries $[7,120]$. For example, at least three servings per day, i.e., approximately $48 \mathrm{~g}$ per day of whole grain cereals, are recommended in USA; three to eight servings per day of grain products at least one-half of them contain whole grains in Canada, at least $50 \mathrm{~g}$ per day of coarse grains including whole grains in China [120]. In the Scandinavian countries, at least $75 \mathrm{~g}$ of whole grain cereals intake per $10 \mathrm{MJ}$ of total energy intake is recommended [40]. Of note, the reported dietary whole grains guidelines are much higher than their average daily consumption (e.g., $42 \mathrm{~g}$ per day in Sweden, $36 \mathrm{~g}$ per day in Denmark). A study by Piironen et al. reported the beneficial influence of whole grains may result from the combined action of fiber, vitamins, phenolic acid, ARs, micronutrients, and other phytochemicals [121]. This suggestion originates from observations that no single antioxidant can replace natural phytochemicals in preventing disease [122]. According to Fardet, there is agreement that the protective effect of whole grain cereals results from the synergistic action of phytochemicals and micronutrients occurring mainly in the bran and germ fractions [7]. To our knowledge, the synergy between phytochemicals present in whole grain cereal products is still not confirmed, due to their huge number and numerous biological functions. However, the evidence on an association of the whole grains consumption and decreased cancer risk is still inconclusive.

\section{Limitations of the study}

When assessing the relationship between AR concentrations and cancer risk, several methodological issues need to be considered. Two of the four analyzed observational studies used semi-reported food frequency questionnaires to assess whole grains intake which is prone to measurement errors in evaluation of associations between dietary intake and risk of civilization diseases [35, 117, 119, 123]. The errors originate from a positive difference between studies in distinct definition of whole grains, a lack of full food composition, large differences of $\mathrm{AR}$ concentrations in whole grain products, variation in AR concentration with time or a dependence of a half-time on the chain length, and variability across studies of serving size. Next, not all observational studies included a list of potential confounders, such as physical activity, fruits, vegetables or red meat intake, ethnicity, and family history of cancer. These variables, which are lacking in the statistical models, might lead to under- or over-estimation of the AR intake/cancer relationship [4, 6, 112, 124-129]. For example, physical activity is considered as an important lifestyle component, of which the association with colorectal cancer risk has been established as conclusive, and with the postmenopausal breast cancer as probable [127, 130]. Moreover, a higher intake of whole grains is usually reported by individuals of healthier lifestyle behaviors, thus all components of lifestyle should be included in statistical analyses as important confounders. Also, some limitations should be acknowledged when interpreting the findings from in vitro studies. The assessment of AR cytotoxicity toward human cancer cell lines may be underestimated because phenolic lipid content and antioxidant activity of plant extracts largely depend on extraction conditions and solvent polarity [56]. Due to fermentation processes, the release of ARs in vivo may be more effective than under in vitro conditions. Furthermore, bioactivity of isolated or synthesized ARs can decline during isolation and storage undergoing oxidation. Also, different methods of processing influence AR concentration in a food. Plasma concentrations of ARs are also influenced by differences in individual absorption and/or metabolism rates. Next, the association of ARs with cancer may by dependent on embryologic origins, on kinds of cancer or subtypes, as seen in observational findings with colorectal cancer (Table 1). Moreover, different sensitivity levels for detection of ARs in biological samples might introduce measurement errors which could explain relatively low AR concentrations in plasma. Finally, misclassification of an outcome when FFQs are used is also probable because ARs are considered in the literature as biomarkers of whole grain wheat and rye intake, only [92]. A correction for measurement errors can enhance the reported associations and weaken the discrepancy between the findings of observational and in vitro studies.

\section{Conclusions}

This systematic review demonstrated a renewed interest in the beneficial effect of ARs on human health. Evidence 
indicates that ARs exhibit a variety of bioactivities; they can affect many physiological and pathological processes related to the immune system, being involved in cell signaling and gene regulation. These findings originate mainly from model and epidemiological studies where assessment of the AR bioactivity in vivo is limited to a few dietary clinical intervention trials. ARs characteristic feature is their potential as biomarkers of whole grain wheat and rye product consumption. There is evidence that individuals with high plasma AR concentrations had above $52 \%$ reduced risk of distal colon cancer with linear dependence originating from biomarker concentration and indirectly from whole grain intake. These findings show that the accuracy of epidemiological studies of whole grain intake and cancer risk based on FFQs may by increased by detection of AR concentration in plasma. In vitro studies show that high-concentration ARs are considered highly cytotoxic agents for certain types of cancer, reporting inhibition of human colon, breast, lung, central nervous, ovarian, cervical, and prostate tumors, and hepatocarcinoma cancer cell lines. Furthermore, the phenolic ring and alkyl chain are important for inhibition of human cancer cells proliferation. This is no common consensus or clarity on the toxicity mechanism toward cancer cells due to multiple AR targets and the complexity of interrelations between various biochemical actions. Observational studies help to evaluate relationships between AR intake and beneficial health effects yet cannot be used to establish causality when compared to intervention studies. The research literature has generated several hypothesized molecular mechanisms of action for ARs in the prevention of cancer and their cytotoxic activities which include the ability to affect all cellular processes regulated by enzymes, suppress an adipocyte lipolysis, affect genotoxicity, have a high affinity to erythrocyte membranes, and exert indirect antioxidant capacity.

Our findings provide further support for public health recommendations emphasizing diets rich in whole grains as potentially preventive against some types of cancer. The updated evidence suggests future studies should focus on identification of a fraction from grain cereals containing concentrations of ARs exerting the strongest cytotoxic effect on cancer cells; this may offer new clues to prevent cancer.

\section{Compliance with ethical standards}

Conflict of interest The authors declare no conflict of interest.

Compliance with ethics requirements This article does not contain any studies with human or animal subjects.
Open Access This article is distributed under the terms of the Creative Commons Attribution 4.0 International License (http://creativecommons.org/licenses/by/4.0/), which permits unrestricted use, distribution, and reproduction in any medium, provided you give appropriate credit to the original author(s) and the source, provide a link to the Creative Commons license, and indicate if changes were made.

\section{References}

1. Sirotkin AV, Harrath AH (2014) Phytoestrogens and their effects. Eur J Pharmacol 741:230-236

2. World Cancer Research Fund/American Institute for Cancer Research (2007) Food, nutrition, physical activity, and the prevention of cancer: a global perspective. Washington DC: AICR, pp 80-116

3. Divisi D, Di Tommaso S, Salvemini S, Garramone M, Crisci R (2006) Diet and cancer. Acta Biomed 77:118-123

4. Key TJ, Allen NE, Spencer EA, Travis RC (2002) The effect of diet on risk of cancer. Lancet 360:861-868

5. Aune D, Chan DSM, Lau R, Vieira R, Greenwood DC, Kampman E, Norat T (2011) Dietary fibre, whole grains, and risk of colorectal cancer: systematic review and dose-response metaanalysis of prospective studies. BMJ 343:d6617

6. Baena R, Salinas P (2015) Diet and colorectal cancer. Mauritas 80:258-264

7. Fardet A (2010) New hypotheses for the health-protective mechanisms of whole-grain cereals: what is beyond fibre? Nutr Res Rev 23:65-134

8. Aggarwal BB, Shishodia S (2006) Molecular targets of dietary agents for prevention and therapy of cancer. Biochem Farmacol 71:1397-1421

9. Androutsopoulos VP, Papakyriakoub A, Vourloumisb D, Tsatsakisa AM, Spandidosc DA (2010) Dietary flavonoids in cancer therapy and prevention: substrates and inhibitors of cytochrome P450 CYP1 enzymes. Pharmacol Therapeut 126:9-20

10. Govind P (2011) Antioxidant vegetables act against cancer and other diseases. IJPSR II:32-38

11. Zhang X, Yeung ED, Wang J, Panzhinsky EE, Tong C, Li W (2010) Isoliquiritigenin, a natural anti-oxidant, selectively inhibits the proliferation of prostate cancer cells. Clin Exp Pharmacol Physiol 37:841-847

12. Liou GY, Storz P (2010) Reactive oxygen species in cancer. Free Radic Res 44:479-496

13. Valko M, Leibfritz D, Moncol J, Cronin MT, Mazur M, Telser J (2007) Free radicals and antioxidant in normal physiological function and human disease. Int J Biochem Cel Biol 39:44-84

14. Romaneiro S, Pareki N (2012) Dietary fiber intake and colorectal cancer risk. Top Clin Nutr 27(1):41-47

15. Luthria DL, Lu Y, John KM (2015) Bioactive phytochemicals in wheat: extraction, analysis, processing, and functional properties. J Funct Foods 18:910-925

16. Reiss J (1989) Influence of alkylresorcinols from rye and related compounds on the growths of food-borne mould. Cereal Chem 66:491-493

17. Iwatsuki K, Akihisa T, Tokuda H, Ukiya M, Higashihara H, Mukainaka T, Iizuka M, Hayashi Y, Kimura Y, Nishino H (2003) Sterol ferulates, sterols, and 5-alk(en)ylresorcinols from wheat, rye, and corn bran oils and their inhibitory effects on EpsteinBarr virus activation. J Agric Food Chem 51:6683-6688

18. Hladyszowski J, Zubik L, Kozubek A (1998) Quantum mechanical and experimental oxidation studies of pentadecylresorcinol, olivetol, orcinol and resorcinol. Free Radic Res 28:359-368 
19. Hallmans G, Zhang JX, Lundin E, Stattin P, Johansson A, Johansson L, Hulten K, Winkvist A, Lenner P, Aman P, Adlercreutz H (2003) Rye, lignans and human health. Proc Nutr Soc 62:193-199

20. Chanson-Rolle A, Meynier A, Aubin F, Lappi J, Poutanen K, Vinoy S, Braesco V (2015) Systematic review and meta-analysis of human studies to support a quantitative recommendation for whole grain intake in relation to type 2 diabetes. PLoS One 10(6):e0131377. doi:10.1371/journal.pone.0131377

21. Shahidi F, Chandrasekara A (2013) Millet grain phenolics and their role in disease risk reduction and health promotion: a review. J Funct Food 5:570-581

22. Seo CR, Yi B, Oh S, Kwon SM, Kim S, Song NJ, Cho JY, Park KM, Ahn JY, Hong JW, Kim MJ, Lee J, Par KW (2015) Aqueous extracts of hulled barley containing coumaric acid and ferulic acid inhibit adipogenesis in vitro and obesity in vivo. J Funct Food 12:208-218

23. Sang S, Zhu Y (2014) Bioactive phytochemicals in wheat bran for colon cancer prevention. In: Watson RR, Predy V, Zibadi $S$ (eds) Wheat and rice in disease prevention and health: benefits, risks and mechanisms of whole grains in health promotion. Academic Press, Waltham, MA, pp 121-129

24. Andersson U, Dey ES, Holm C, Degerman E (2011) Rye bran alkylresorcinols suppress adipocyte lipolysis and hormone-sensitive lipase activity. Mol Nutr Food Res 55(Suppl 2):290-293

25. Korycińska M, Czelna K, Jaromir A, Kozubek A (2009) Antioxidant activity of rye bran alkylresorcinols and extracts from whole-grain cereal products. Food Chem 116:1013-1018

26. Kulawinek M, Kozubek A (2007) 5- $n$-Alkylresorcinols of whole grain cereals and whole grain cereal products as biomarkers of healthy food. Postępy Biochemii 53(3):287-296

27. Kozubek A, Tyman JHP (1999) Resorcinol lipids, the natural non-isoprenoid phenolic amphiphiles and their biological activity. Chem Rev 99:1-25

28. Siurek B, Rosicka-Kaczmarek J, Nebesny E (2011) Bioactive compounds in cereal grains-occurrence, structure, technological significance and nutritional benefits-a review. Food Sci Technol Int 18(6):559-568

29. Söderholm PP, Lundin JE, Koskela AH, Tikkanen MJ, Adlercreutz HC (2011) Pharmacokinetics of alkylresorcinols metabolites in human urine. Br J Nutr 106:1040-1044

30. Crauste C, Rosell M, Durand T, Vercauteren J (2016) Omega-3 polyunsaturated lipophenols, how and why? Biochimie 120:62-74

31. Andersson AAM, Kamal-Eldin A, Åman P (2010) Effects of environment and variety on alkylresorcinols in wheat in the HEALTHGRAIN diversity screen. J Agric Food Chem 58:9299-9305

32. Gunenc A, HadiNezhad M, Tamburic-Ilincic L, Mayer PM, Hosseinian F (2013) Effect of region and cultivar on alkylresorcinols content and composition in wheat bran and their antioxidant activity. J Cereal Sci 57(3):405-410

33. Landberg R, Kamal-Eldin A, Andersson A, Vessby B, Aman P (2008) Alkylresorcinols as biomarkers of whole-grain wheat and rye intake: plasma concentration and intake estimated from dietary records. Am J Clin Nutr 87:832-838

34. Ross AB, Kochhar S (2009) Rapid and sensitive analysis of alkylresorcinols from cereal grains and products using HPLCCoularray-based electrochemical detection. J Agric Food Chem 57:5187-5193

35. Landberg R, Townsend MK, Neelakantan N, Sun Q, Sampson L, Spiegelman D, van Dam RM (2012) Alkylresorcinol metabolite concentrations in spot urine samples correlated with whole grain and cereal fiber intake but showed low to modest reproducibility over one to three years in U.S. women. J Nutr 142:872-877
36. Ross AA, Bourgeois A, Macharia HN, Kochhar S, Jebb SA, Brownlee IA, Seal CJ (2012) Plasma alkylresorcinols as a biomarker of whole-grain food consumption in a large population: results from the WHOLEheart Intervention Study. Am J Clin Nutr 95:204-211

37. Andersson AAM, Dimberg L, Åman P, Landberg R (2014) Recent findings on certain bioactive components in whole grain wheat and rye. J Cent Sci 59:294-311

38. Ross AB (2012) Present status and perspectives on the use of alkylresorcinols as biomarkers of whole grain wheat and rye intake. J Nutr Metab. doi:10.1155/2012/462967

39. Stevenson L, Phillips F, O'sullivan K, Walton J (2012) Wheat bran: its composition and benefits to health, a European perspective. Int J Food Sci Nutr 63(8):1001-1013

40. Frølich W, Åman P, Tetens J (2013) Whole grain foods and health: a Scandinavian perspective. Food Nutr Res 57:18503. doi:10.3402/fnr.v57i0.18503

41. Prückler M, Siebenhandl-Ehn S, Apprich S, Höltinger S, Haas C, Schmid E, Kneifel W (2014) Wheat bran-based biorefinery 1: composition of wheat bran and strategies of functionalization. LWT Food Sci Tech 56:211-221

42. Ross AB, Kamal-Eldin A, Aman P (2004) Dietary alkylresorcinols: absorption, bioactivities, and possible use as biomarkers of whole-grain wheat- and rye-rich foods. Nutr Rev 62:81-95

43. McKevith B (2004) Nutritional aspects of cereals. Nutr Bull 29:111-142

44. Sorghum and millets in human nutrition, FAO Food and Nutrition Series, No. 27 (1995) Rome, Chap 6, pp 63-104. http:// www.fao.org/docrep/T0818e/T0818E00.htm\#Contents. Accessed 31 Dec 2016

45. Nadeem N, Anjum FM, Amir RM, Khan MR, Hussain S, Javed MS (2010) An overview of anti-nutritional factors in cereal grains with special reference to wheat: a review. Pak J Food Sci 20(1-4):54-61

46. Onipe OO, Jideani AIO, Beswa D (2015) Composition and functionality of wheat bran and its application in some cereal food products. Int J Food Sci Tech 50:2509-2518

47. Bordiga M, Locatelli M, Travaglia F, Arlorio M, Reyneri A, Blandino M, Coisson JD (2016) Alkylresorcinol content in whole grains and pearled fractions of wheat and barley. J Cereal Sci 70:38-46

48. Landberg R, Marclund M, Kamal-Eldin A, Aman P (2014) An update on alkylresorcinols - occurrence, bioavailability, bioactivity and utility as biomarkers. J Funct Foods 7:77-89

49. Aubertin-Leheudre M, Koskela A, Marjamaa A, Adlercreutz H (2008) Plasma alkylresorcinols and urinary alkylresorcinol metabolites as biomarkers of cereal fiber intake in Finnish women. Cancer Epidemiol Biomark Prev 17:2244-2248

50. Söderholm PP, Koskela AH, Lundin JE, Tikkanen MJ, Adlercreutz HC (2009) Plasma pharmacokinetics of alkylresorcinol metabolites: new candidate biomarkers for whole-grain rye and wheat intake. Am J Clin Nutr 90:1167-1171

51. Zhu Y, Shurlknight KL, Chen X, Sang S (2014) Identification and pharmacokinetics of novel alkylresorcinol metabolites in human urine, new candidate biomarkers for whole-grain wheat and rye intake. J Nutr 144:114-122

52. Wierzbicka R (2017) New alkylresorcinol metabolites. Identification, quantification and evaluation as dietary biomarkers. Doctoral Thesis, Swedish Univ Agricult Sci Uppsala, Acta Universitatis Agriculture Sueciae (1652-6880). 2017:2046-2055

53. Herrero M, Cifuentes A, Ibañez E (2006) Sub- and supercritical fluid extraction of functional ingredients from different natural sources: plans, food-by-products, algae and microalgae: a review. Food Chem 98:136-148

54. da Francisco JC, Danielsson B, Kozubek A, Szwajcer Dey E (2005) Alkylresorcinols extracted from rye seeds by 
supercritical carbon dioxide. www.isasf.net/fileadmin/files/ Docs/Trieste/Papers/N14.pdf. Accessed 10 Jan 2017

55. Vinatoru M (2001) An overview of the ultrasonically assisted extraction of bioactive principles from herbs. Ultrason Sonochem 8:303-313

56. Falleh H, Ksouri R, Lucchessi M-E, Abdelly C, Magné C (2012) Ultrasound-assisted extraction: effect of extraction time and solvent power on the levels of polyphenols and antioxidant activity of Mesembryanthemum edule L. Aizoaceae shots. Tropic J Pharm Res 11(2):243-249

57. Landberg R, Dey ES, Da CruZ FJ, Åman P, Kamal-Eldin A (2007) Comparison of supercritical carbon dioxide and ethyl acetate extraction of alkylresorcinols from wheat and rye. $\mathbf{J}$ Food Comp Anal 20:534-538

58. Zhu Y, Soroka DN, Sang S (2012) Synthesis and inhibitory activities against colon cancer cell growth and proteasome of alkylresorcinols. J Agric Food Chem 60:8624-8631

59. Landberg R, Man P, Kamal-Eldin A (2009) A rapid gas chromatography-mass spectrometry method for quantification of alkylresorcinols in human plasma. Anal Biochem 385:7-12

60. Masuoka N, Nihei K, Maeta A, Yamagiwa Y, Kubo I (2015) Inhibitory effects of cardols and related compounds on superoxide anion generation by xanthine oxidase. Food Chem 166:270-274

61. Anderson A, Marklund M, Diana M, Landberg R (2011) Plasma alkylresorcinol concentrations correlate with whole grain wheat and rye intake and show moderate reproducibility over a 2- to 3-month period in free-living Swedish adults. J Nutr 141:1712-1718

62. Landberg R, Kamal-Eldin AP, Christensen J, Overvad K, Tjønneland A, Olsen A (2011) Determinants of plasma alkylresorcinol concentration in Danish post-menopausal women. Eur J Clin Nutr 65:94-101

63. Landberg R, Kamal-Eldin A, Anderson SO, Johansson JE, Zhang JX, Hallmans G, Man P (2009) Reproducibility of plasma alkylresorcinols during a 6-week rye intervention study in men with prostate cancer. J Nutr 139:975-980

64. Montonen J, Landberg R, Kamal-Eldin A, Åman P, Boeing H, Steffen A, Pischon T (2012) Reliability of fasting plasma alkylresorcinol metabolites concentrations measured 4 months apart. Eur J Clin Nutr 66:968-970

65. Biskup I, Kyrø C, Marklund M, Olsen A, van Dam RM, Tjønneland A, Overvad K, Lindahl B, Johansson I, Landberg R (2016) Plasma alkylresorcinols, biomarkers of whole-grain and rye intake, and risk of type 2 diabetes in Scandinavian men and women. Am J Clin Nutr 104:88-96

66. Aubertin-Leheudre M, Koskela A, Samaletdin A, Adlercreutz $H$ (2010) Plasma and urinary alkylresorcinol metabolites as potential biomarkers of breast cancer risk in Finnish women: a pilot study. Nutr Cancer 62:759-764

67. Meija L, Krams I, Cauce V, Samaletdin A, Söderholm P, Meija R, Lārmane L, Lejnieks A, Lietuvietis V, Adlercreutz $\mathrm{H}$ (2015) Alkylresorcinol metabolites in urine and plasma potential biomarkers of rye and wheat fiber consumption in prostate cancer patients and controls. Nutr Cancer 67:258-265

68. Kyrø C, Olsen A, Bueno-de-Mesquita HB, Skeie G, Loft S, Aman P, Leenders M, Dik VK, Siersema PD, Pischon T, Christensen J, Overvad K, Boutron-Ruault MC, Fagherazzi G, Cottet V, Kühn T, Chang-Claude J, Boeing H, Trichopoulou A, Naska A, Oikonomidou D, Masala G, Pala V, Tumino R, Vineis P, Mattiello A, Peeters PH, Bakken T, Weiderpass E, Asli LA, Sánchez S, Jakszyn P, Sánchez MJ, Amiano P, Huerta JM, Barricarte A, Ljuslinder I, Palmqvist R, Khaw KT, Wareham N, Key TJ, Travis RC, Slimani N, Freisling H, Ferrari P, Gunter MJ, Murphy N, Riboli E, Tjønneland
A, Landberg R (2014) Plasma alkylresorcinol concentrations, biomarkers of whole-grain wheat and rye intake, in the European Prospective Investigation into Cancer and Nutrition (EPIC) cohort. Br J Nutr 111:1881-1890

69. Drake I, Sonestedt E, Gullberg B, Bjartell A, Olsson H, Adlercreutz H, Tikkanen MJ, Wirfãlt E, Wallström P (2013) Plasma alkylresorcinol metabolites as biomarkers for whole-grain intake and their association with prostate cancer: a Swedish nested case-control study. Cancer Epidemiol Biomark Prev 23:73-83

70. Luis LA, Domingues F, Duarte AP (2016) Biological properties of plant-derived alkylresorcinols: mini-review. Mini Rev Med Chem 16:851-854

71. Gąsiorowski K, Szyba K, Brokos B, Kozubek A (1996) Antimutagenic activity of alkylresorcinols from cereal grains. Cancer Lett 106:109-115

72. Gąsiorowski K, Brokos B, Kulma A, Ogorzałek A, Skórkowska $\mathrm{K}$ (2001) Impact of four antimutagens on apoptosis in genotoxically damaged lymphocytes in vitro. Cell Mol Biol Lett 6:649-675

73. Adlercreutz H (2010) Can rye intake decrease risk of human breast cancer? Food Nutr Res 54:5231. doi:10.3402/fnr. v54i0.5231

74. Borneo R, León AE (2012) Whole grain cereals: functional components and health benefits. Food Funct 3:110-119

75. Koh-Banerjee P, Rimm EB (2003) Whole grain consumption and weight gain: a review of the epidemiological evidence, potential mechanisms and opportunities for future research. Proc Nutr Soc 62:25-29

76. La Vecchia C, Chatenoud L, Negri E, Franceschi S (2003) Session: whole cereals grains fibre and human cancer. Whole grain cereals and cancer in Italy. Proc Nutr Soc 62:45-49

77. Pereira MA, Jacobs DR, Pins JJ, Raatz SK, Gross MD, Slavin JL, Seaquist ER (2002) Effect of whole grains on insulin sensitivity in overweight hyperinsulinemic adults. Am J Clin Nutr 75:848-855

78. Ye EQ, Chacko SA, Chou EL, Kugizaki M, Liu S (2012) Greater whole-grain intake is associated with lower risk of type 2 diabetes, cardiovascular disease, and weight gain. J Nutr 142:1304-1313

79. Ross AB, Chen Y, Frank J, Swanson JE, Parker RS, Kozubek A, Lundh T, Vessby B, Aman P, Kamal-Eldin A (2004) Cereals alkylresorcinols elevate $\gamma$-tocopherol levels in rats and inhibit $\gamma$-tocopherol metabolism in vitro. J Nutr 134:506-510

80. Perry RJ, Samuel VT, Petersen KF, Shulman GI (2014) The role of hepatic lipids in hepatic insulin resistance and type 2 diabetes. Nature 510:84-91

81. Söderholm PP, Alfthan G, Tikkanen MJ, Adlercreutz H (2012) Rye bread intake improves oxidation resistance of LDL in healthy humans. Atherosclerosis 221:583-586

82. Parikka K, Rowland IR, Welch RW, Wähälä K (2006) In vitro antioxidant activity and antigenotoxicity of 5-n-alkylresorcinols. J Agric Food Chem 54:1646-1650

83. Gliwa J, Gunenc A, Ames N, Willmore WG, Hosseinian FS (2011) Antioxidant activity of alkylresorcinols from rye bran and their protective effect on cell viability of PC-12 AC cells. J Agric Food Chem 59:11473-11482

84. Barbini L, Lopez P, Ruffa J, Martino V, Ferraro G, Campos R, Cavallaro L (2006) Induction of apoptosis on human hepatocarcinoma cell lines by an alkyl resorcinol isolated from Lithraea molleoides. World J Gastroenterol 12:5959-5963

85. Linko-Parvinen AM, Landberg R, Tikkanen MJ, Adlercreutz H, Peñalvo JL (2007) Alkylresorcinols from whole-grain wheat and rye are transported in human plasma lipoproteins. J Nutr 137:1137-1142

86. Halliwell B, Gutteridge JM (1995) The importance of free radicals and catalytic metal ions in human diseases. Mol Aspects Med 8:89-193 
87. Vaher M, Matso K, Levandi T, Helmja K, Kaljurand M (2010) Phenolic compounds and the antioxidant activity of the bran, flour and whole grain of different wheat varieties. Proc Chem 2:76-82

88. Brownlee IA, Moore C, Chatfield M, Richardson DP, Ashby P, Kuznesof SA, Jebb SA, Seal CJ (2010) Markers of cardiovascular risk are not changed by increased whole-grain intake: the WHOLEheart study, a randomised, controlled dietary intervention. Br J Nutr 104:125-134

89. Tighe P, Duthie G, Vaughan N, Brittenden J, Simpson WG, Duthie S, Mutch W, Wahle K, Horgan G, Thies F (2010) Effect of increased consumption of whole-grain foods on blood pressure and other cardiovascular risk markers in healthy middle-aged persons: a randomized controlled trial. Am J Clin Nutr 92:733-740

90. Kristensen M, Toubro S, Jensen MG, Ross AB, Riboldi G, Petronio M, Bugel S, Tetens I, Astrup A (2012) Whole grain compare with refined wheat decreases the percentage of body fat following a 12-week, energy-restricted dietary intervention in postmenopausal women. J Nutr 142:710-716

91. Rave K, Roggen K, Dellweg S, Heise T, Dieck HT (2007) Improvement of insulin resistance after diet with a whole-grain based dietary product: results of a randomized, controlled crossover study in obese subject with elevated fasting blood glucose. Br J Nutr 98:926-936

92. Kyrø C, Olsen A, Landberg R, Skeie G, Loft S, Ĺman P et al (2014) Plasma alkylresorcinols, biomarkers of whole-grain wheat and rye intake, and incidence of colorectal cancer. JNCI J Natl Cancer Inst 106:djt352

93. Knudsen MD, Kyrø C, Olsen A, Dragsted LO, Skeie G, Lund E, Åman P, Nilsson LM, Bueno-de-Mesquita HB, Tjønneland A, Landberg R (2014) Self-reported whole-grain intake and plasma alkylresorcinol concentrations in combination in relation to the incidence of colorectal cancer. Am J Epidemiol 79:1188-1196

94. Olsen A, Landberg R, Aman P, Kamal-Eldin A, Christensen J, Føns-Johnsen N, Overvad K, Tjønneland A (2010) Plasma levels of alkylresorcinols and incidence of endometrial cancer. Eur J Cancer Prev 19:73-77

95. Nimptsch K, Kenfield S, Jensen MK, Stampfer MJ, Franz M, Sampson L, Brand-Miller JC, Willett WC, Giovannucci E (2011) Dietary glycemic index, glycemic load, insulin index, fiber and whole-grain intake in relation to risk of prostate cancer. Cancer Causes Control 22:51-61

96. Zhu Y, Conklin DR, Chen H, Wang L, Sang S (2011) 5-Alk(en) ylresorcinols as the major active components in wheat bran inhibit human colon cancer cell growth. Bioorg Med Chem 19:3973-3982

97. Sánchez LA, Olmedo D, López-Pérez JL, Williams TD, Gupta MP (2012) Two new alkylresorcinols from Homalomena wendlandii and their cytotoxic activity. Natur Prod Commun 7:1043-1046

98. Chuang TH, Wu PL (2007) Cytotoxic 5-Alkylresorcinol metabolites from the leaves of Grevillea robusta. J Nat Prod 70:319-323

99. Liu L, Winter KM, Stevenson L, Morris C, Leach DN (2012) Wheat bran lipophilic compounds with in vitro anticancer effects. Food Chem 130:156-164

100. Chaturvedula VSP, Schilling JK, Miller JS, Andriantsiferana R, Rasamison VE, Kingston DGI (2002) New cytotoxic bis 5-alkylresorcinol derivatives from the leaves of Oncostemon bojerianum from the Madagascar rainforest. J Nat Prod 65:1627-1632

101. Al-Mekhlafi NA, Shaari K, Abas F, Kneer R, Jeyaraj EJ, Stanlas J, Yamamoto N, Honda T, Lajis NH (2012) Alkylresorcinols and cytotoxic activity of the constituents isolated from Labisia pumila. Phytochem 80:42-49
102. Kubo I, Ochi M, Vieira PC, Komatsu S (1993) Antitumor agents from the cashew (Anacardium occidentale) apple juice. J Agric Food Chem 41:1012-1015

103. Vila-Luna SE, Moo-Puc RE, Torres-Tapia LW, Pereza-Sánchez SR (2017) New metabolites with cytotoxic and antiproliferative activities isolated from Bonellia macrocarpa. Phytochem Lett 19:121-125

104. Lowe SW, Ruley HE, Jacks T, Housman DE (1993) p53-dependent apoptosis modulates the cytotoxicity of anticancer agents. Cell 74:957-967

105. Arisawa M, Ohmura K, Kobayashi A, Morita N (1989) A cytotoxic constituent of Lysimachia japonica Thunb. (Primulaceae) and the structure-activity relationships of related compounds. Chem Pharm Bull (Tokyo) 37:2431-2434

106. Barr JR, Murty VS, Yamaguchi K, Singh S, Smith PH, Hecht SM (1988) 5-Alkylresorcinols from Hakea amplexicaulis that cleave DNA. Chem Res Toxicol 1:204-207

107. Chen GC, Tong X, Xu JY, Han SF, Wan ZX, Qin JB, Qin LQ (2016) Whole-grain intake and total, cardiovascular, and cancer mortality: a systematic review and meta-analysis of prospective studies. Am J Clin Nutr 104:164-172

108. Singh US, Scannell RT, An H, Carter BJ, Hecht SM (1995) DNA cleavage by di- and trihydroxyalkylbenzenes. Characterization of products and the roles of $\mathrm{O}_{2}, \mathrm{Cu}(\mathrm{II})$, and alkali. J Am Chem Soc 117:12691-12699

109. Sumino M, Sekine T, Ruangrungsi N, Igarashi K, Ikegami F (2002) Ardisiphenols and other antioxidant principles from the fruits of Ardisia colorata. Chem Pharm Bull (Tokyo) 50:1484-1487

110. WCRF/AICR (2011) Continuous update project interim report summary. Food, nutrition, physical activity, and prevention of colorectal cancer. http://www.wcrf.org/cancer_research/cup/ key_findings/colorectal_cancer.php. Accessed 26 Nov 2016

111. Stasiuk M, Kozubek A (2010) Biological activity of phenolic lipids. Cell Mol Life Sci 67:841-860

112. Ruiz RB, Hernández PS (2014) Diet and cancer: risk factors and epidemiological evidence. Maturitas 77:202-208

113. Rejman J, Kozubek A (2004) Inhibitory effect of natural phenolic lipids upon NAD-dependent dehydrogenases and on triglyceride accumulation in 3T3-L1 cells in culture. J Agric Food Chem 52:246-250

114. European Food Information Council (EUFIC). Whole grain fact sheet. Available from www.eufic.org/article/en/page/ BARCHIVE/expid/whole-grain-fact-sheet. Cited 15 July 2015

115. Frølich W, Aman P (2010) Whole grain for whom and why? Food Nutr Res 54:1-5

116. Liu MM, Huang Y, Wang J (2012) Developing phytoestrogens for breast cancer prevention. Anticancer Agents Med Chem 12:1306-1313

117. Ross AB, Kristensen M, Seal CJ, Jacques P, McKeown NM (2015) Recommendations for reporting whole-grain intake in observational and intervention studies. Am J Clin Nutr 101:903-907

118. US Department of Agriculture and US Department of Health and Human Services. Dietary guidelines for Americans. http:// www.choosemyplate.gov/dietary-guidelines.html. Accessed 6 Dec 2016

119. Kantor LS, Krebs-Smith SM, Variyam JN, Allshouse JE, Putnam JJ, Lin BH (2001) Choose a variety of grains daily, especially whole grains: a challenge for consumers. J Nutr 131(2S-1):473S-486S

120. Ferruzzi MG, Jonnalagadda SS, Liu S, Marquart L, McKeown N, Reick M, Riccardi G, Seal C, Slavin J, Thielecke F, van der Kamp J-W, Webb D (2014) Developing a standard definition of whole-grain food for expert roundtable discussion. Adv Nutr 5:164-176 
121. Pirronen V, Lampi A-M, Ekholm P, Salmenkallio-Marttila M, Liukkonen KH (2009) Micronutrients and phytochemicals in wheat grain. In: Khan K, Shewry PR (eds) Wheat: chemistry and technology, 4th edn. AACC International, St. Paul, MN, pp $179-222$

122. Liu RH (2004) Potential synergy of phytochemicals in cancer prevention: mechanism of action. J Nutr 134:3479S-3485S

123. Kipnis V, Subar AF, Mitthune D, Freedman LS, Ballard-Barbash R, Troiano RP, Bingham S, Schoeller DA, Schatzkin A, Carroll RJ (2003) Structure of dietary measurement error: results of the OPEN biomarker study. Am J Epidemiol 158:14-21

124. Tucker AJ, Vandermey JS, Robinson LE, Graham TE, Bakovic M, Duncan AM (2014) Effects of breads of varying carbohydrate quality on postprandial glycaemic, incretin and lipidaemic response after first and second meals in adults with diet-controlled type 2 diabetes. J Funct Foods 6:116-125

125. Meng H, Hu W, Chen Z, Shen Y (2014) Fruit and vegetable intake and prostate cancer risk: a meta-analysis. Asia Pac J Clin Oncol 10:133-140
126. Koutsokera A, Kiagia M, Saif MW, Souliotis K, Syrigos KN (2013) Nutrition habits, physical activity, and lung cancer: an authoritative review. Clin Lung Cancer 14:342-350

127. Boyle T, Keegel T, Bull F, Heyworth J, Fritschi L (2012) Physical activity and risk of proximal and distal colon cancers: a systematic review and meta-analysis. J Natl Cancer Inst 104:1548-1561

128. Kruk J (2014) Lifestyle components and primary breast cancer prevention. Asian Pac J Cancer Prev 15:10543-10555

129. Amin TT, Al-Hammam AM, AlMulhim NA, Al-Hayan MI, AlMulhim MM, Al-Mosabeh MJ, Al-Subaie MA, Al-Hmmad QA, Al-Omran AA (2014) Physical activity and cancer prevention: awareness and meeting the recommendations among adult Saudis. Asian Pac J Cancer Prev 15:2597-2606

130. Kruk J, Czerniak U (2013) Physical activity and its relation to cancer risk: updating the evidence. Asian Pac Cancer Prev 14:3993-4003 